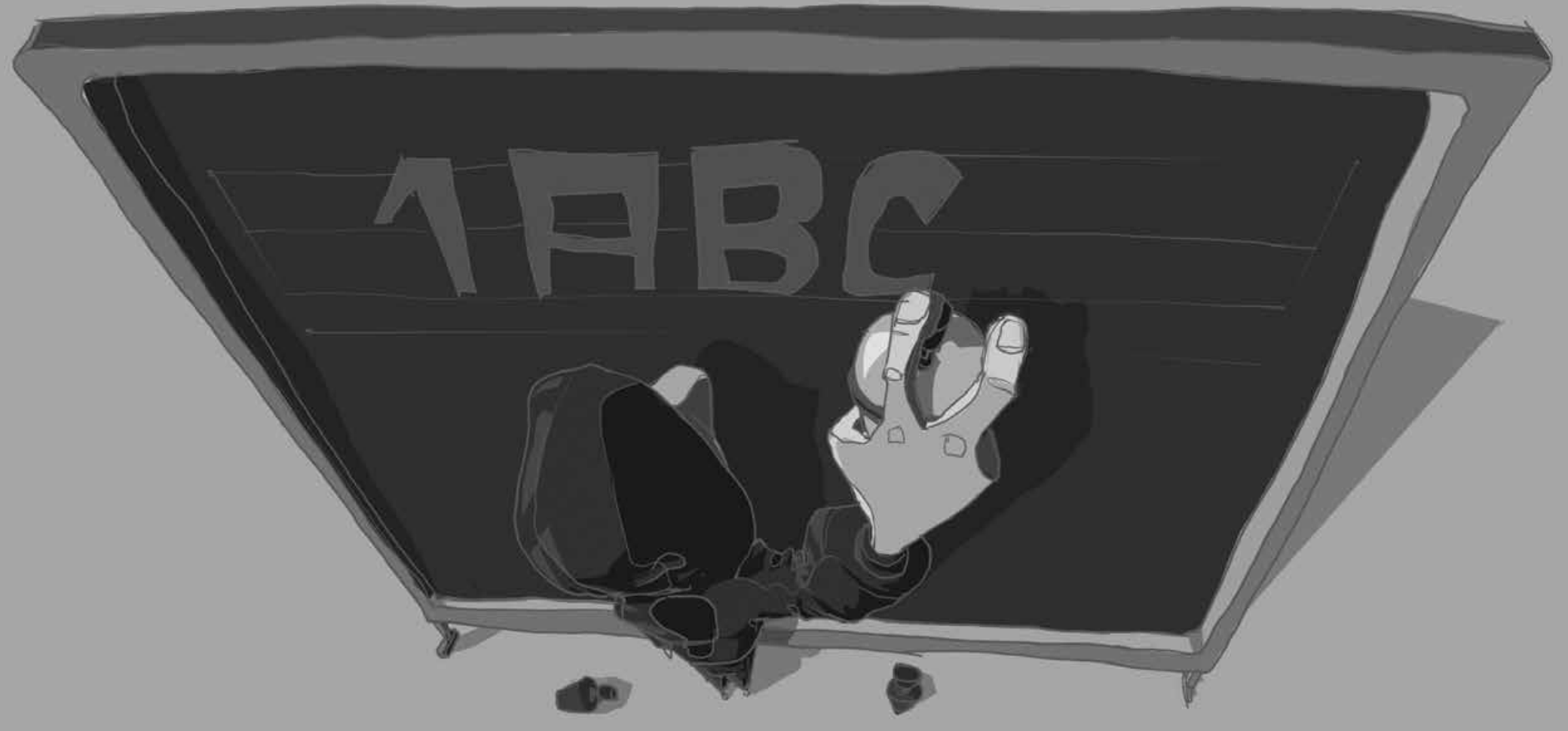

\title{
Resignificación del grafiti como expresión escrita en la escuela ${ }^{1}$
}

Redefinition of graffiti as writing in school Redefinição do graffiti como escrever na escola 
2. Licenciado en Lenguas Modernas español, inglés, de la Universidad Distrital Francisco José de Caldas. Docente de la Secretaría de Educación del Distrito, SED, en el CED La Concepción. Correo electrónico: felinosextremos@yahoo.es

\section{Resumen}

El presente artículo adelanta una reflexión teórica sobre la producción de un texto de carácter estético, enmarcado en el contexto escolar como el grafiti, muy significativo y recurrente en el entorno comunicativo de los estudiantes. De esta manera, el propósito es realizar una disertación teórica sobre su evolución discursiva a nivel histórico y funcional; además, establecer la relación del grafiti como posibilidad metodológica para la enseñanza de la escritura en la escuela.

Palabras clave: Escritura, grafiti y textos estéticos.

\section{Summary}

This article advances a theoretical reflection on the production of a text of aesthetic, framed in the school context as graffiti is very significant, recurring in the media environment of the students. Thus, the purpose is to make a theoretical dissertation on the historical discursive and practical level to evolution; also establish the relationship of graffiti as methodological possibility for writing instruction in school.

Key words: Writing, graffiti and aesthetic texts.

\section{Resumo}

Este artigo propõe uma reflexão teórica sobre a produção de um caráter estético texto, definido no contexto escolar como grafite, muito significativa e recorrente no ambiente comunicativo para os alunos. Assim, o objetivo é fazer uma dissertação teórica sobre a evolução histórica e discursiva nível funcional; também estabelecer a relação de graffiti como possibilidade metodológica para o ensino da escrita na escola.

Palavras chave: Redação, graffiti e textos estéticos. 


\section{Introducción}

_. oy, la competencia comunicativa de los estudiantes de

secundaria cobra una gran importancia en los procesos de enseñanza y aprendizaje, no sólo en el área del lenguaje, sino en las demás áreas del conocimiento. La escritura, como una de las habilidades y actividades discursivas que más preocupa a los agentes de la escuela, se convierte en un objeto de investigación sobre el cual el quehacer pedagógico del maestro reflexiona constantemente, haciendo posible así, la aplicación de estrategias metodológicas que permiten mejorar los niveles de escritura en los estudiantes. Esta tendencia se confirma cuando se da una mirada a las investigaciones que, sobre la producción textual como parte de la modalidad escrita de la lengua, han sido objeto de reflexión en los últimos años por varios teóricos (V.gr. Jolibert, 1992; Van Dijk, 2006; Cassany, 2008; Eco, 1994, et., al) quienes la asumen como un proceso que implica habilidades cognitivas, lingüísticas y socioculturales.

En el devenir de estas investigaciones sobre composición escrita en la escuela, resulta llamativa la producción de textos estéticos, entre ellos el grafiti, textura que circula de forma silenciosa en el entorno físico de la escuela, del barrio o de la ciudad, y que ha sido objeto de preocupación por parte de la semiótica cultural y urbana, pero no por la pedagogía de la lengua materna que permitiría asociar textos de esta naturaleza con procesos escritos en las nuevas capas de la escuela. Lo anterior, invita a realizar un recorrido sobre los antecedentes teóricos que suscitan el entendimiento seudo lingüístico y social de este tipo de textos de carácter urbano, y que implica un proceso de escritura en el cual confluyen aspectos socioculturales, semióticos y políticos que se pueden tomar como herramienta para el mejoramiento de la escritura en la escuela.

Para esta reflexión se tomarán como referencia estudios realizados por varios autores, entre ellos Umberto Eco y Armando Silva Téllez; el primero cualificando la naturaleza del grafiti como texto estético y el segundo proporcionando una mirada de la evolución del grafiti como expresión urbana desde los años sesenta hasta la actualidad. Por otra parte, se establecerá una relación con la escuela y las posibilidades metodológicas que suscita el texto estético para la aplicación de estrategias y el fortalecimiento del proceso escritor de los estudiantes. 


\section{El enigmático mundo del grafiti}

Silva Armando (2013) llama grafiti a la palabra plural tomada del italiano graffito, del griego graphis que significa carbono natural para las minas de los lápices y se hace extensivo a la grafía. Lo anterior, hace referencia a varias formas de inscripción o pintura (pintadas o pintas) que se realizan sobre el mobiliario urbano. Por otra parte, si caracterizamos el grafiti como texto estético, Umberto Eco (1986) propone una apuesta conceptual en relación con los aspectos semánticos y pragmáticos. También considera unas funciones del leguaje soportadas en Jakobson que favorecen la intención del autor. Además, la plurisignificación del mensaje a partir de la ambigüedad del mismo; generando así, sorpresa, credibilidad, verosimilitud y un sentido crítico o auto reflexivo de la realidad.

Ahora bien los grafitis se pueden clasificar según su estilo como:

- Nichos estéticos, grafiti con significados semióticos, no solo con la intención de promover denuncias políticas, sino con un sentido social que permiten transformar la realidad urbana y su entorno específico. Existe el nicho, cuando permite producir asombro, crítica, actitud y posición frente al mensaje por parte de los espectadores.

- Los tags que hace referencia a la escritura del nombre o apodo de los grafiteros por diferentes lugares o muros, el más famoso fue el de Taki 183 de un mensajero de Filadelfia, quien lo popularizó y dio origen a este gran fenómeno.

- Los slogans que se estructuran a partir de temas específicos, llegando a los demás en forma natural y combinando el texto con la imagen.

- La latrinilla o grafiti privado que generalmente se encuentra en los baños ya sea en sus paredes, espejos o puertas y que logran desconcertar o reflexionar al espectador.

La composición o estructuración del grafiti, (Silva, 2013), se encuentra sujeta a una serie de valencias o cargas semánticas que permiten identificar sus elementos y realizar un análisis semiótico sobre su contenido comunicativo, urbano y social.

Las valencias a identificar son la marginalidad que se aleja del contexto formal de la sociedad por razones ideológicas, el anonimato que resguarda y protege a su creador y da paso a la autoría de un grupo que los representa, la espontaneidad como la necesidad de aprovechar el instante y la oportunidad del trazo, la escenicidad como la tendencia de publicar el grafiti para impactar al posible lector con sus colores y diseños, la velocidad como el tiempo fugaz para la elaboración del grafiti por cuestiones de

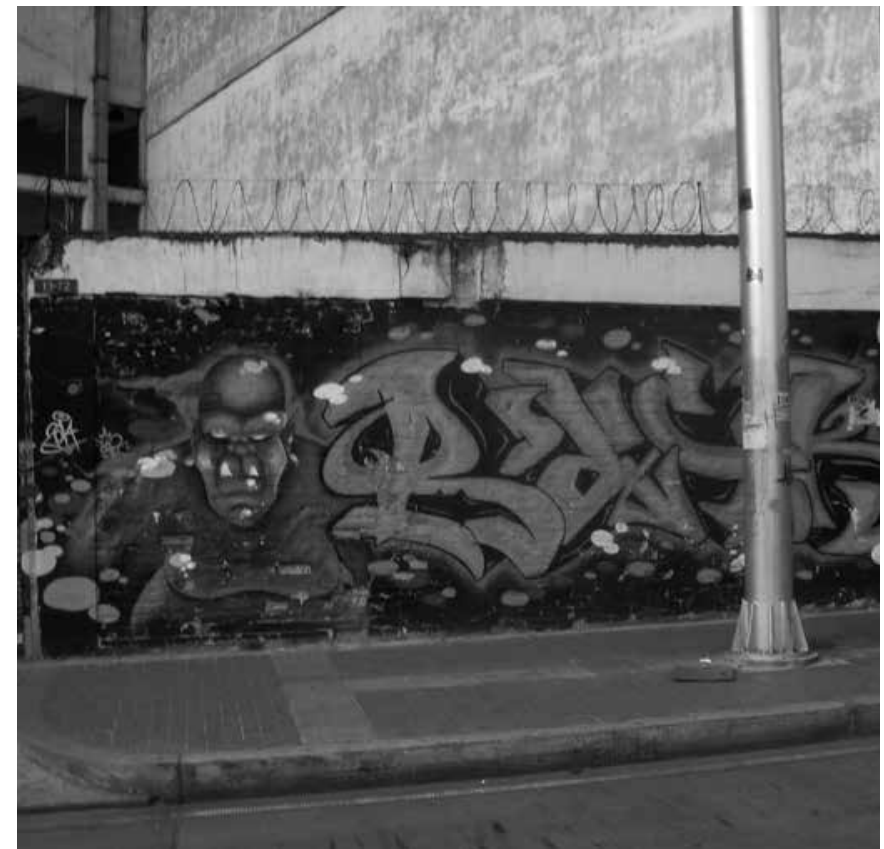

Bogotá, Calle 26 con carrera 13. Colección de César Correa Neira. 2014

seguridad, la precariedad en el manejo de materiales de bajo costo y su adquisición y la fugacidad como el tiempo impredecible de la duración del grafiti en el muro.

Estas valencias contribuyeron a formalizar el grafiti y en este sentido, se puede hacer un recorrido cronológico de los momentos más significativos de este fenómeno.

Los arqueólogos y epigrafistas lo consideran como inscripciones espontáneas que han quedado en las paredes desde tiempos antiguos con el imperio egipcio y romano mediante sus representaciones jeroglíficas o rupestres. En la década de los sesenta con el fenómeno del writing en Nueva York se pasa de los pinceles a la utilización de los aerosoles. Luego, en los años setenta se presenta un auge con el style war donde se competía por elevar su calidad e impacto en las urbes de Norte América. Posteriormente, surge el fenómeno del hip hop que lo consideraba como uno de los elementos fundamentales de la cultura; llamándose, a sí mismos, escritores que con sus firmas plasmadas en los muros dieron origen a los tags, throw-up y los piece, este último es el más popularizado en la actualidad (Méndez y Garrido, 2002).

El fenómeno social del grafiti en Colombia (Silva, 1986) surge a partir de las protestas juveniles en las universidades y en las luchas sindicales de varios grupos sociales, las cuales utilizaban 
este medio de expresión para denunciar, atacar y censurar el sistema político y económico imperante, puesto que los medios masivos de comunicación controlados no lo permitían. Los muros de las universidades, los baños públicos, las calles marginales y los demás lugares públicos eran el lienzo perfecto para inscribir al grafiti. Por otro lado, la clandestinidad y la fugacidad en su elaboración fueron una característica reiterada de los grafiteros, quienes en la elaboración de estas texturas se exponían a ser atrapados, porque se consideraba un delito, en casos extremos, eran detenidos en las estaciones de policía. Estas acciones implicaban, de suyo, que el grafiti era determinado como una puesta en escena territorial, manifestándose como un antecedente histórico, ideológico y estético de las acciones urbanas.

A finales del siglo XX y comienzos del XXI el grafiti ya no es considerado un texto plenamente espontáneo, puesto que cuenta con un pensamiento elaborado, una intención y un diseño planificado, sin olvidar los factores de riesgo a nivel personal y social. Los grafiteros materializan estas texturas en representaciones cargadas de anhelos, frustraciones, miedos y reflexiones sociales de la realidad circundante en la mente de los transeúntes. La pared en blanco, como la llaman ellos, es el escenario virgen donde la población en constante deshumanización logra violar y pintar con su spray de mil colores un imaginario colectivo que lucha por desahogar las ideas en contra de un sistema imperante.

En la actualidad y gracias a las políticas públicas de diferentes ciudades, el grafiti ha tenido una evolución a nivel urbanístico, lo que genera una agudeza estética en su diseño y elaboración. Esto ha permitido el tránsito paulatino al arte callejero. En sus dimensiones podemos observar un equilibrio entre la semiología del grafiti y la naturaleza del arte mismo, expresada en su composición, color, forma, espacio y estableciendo un diálogo constante con el entorno. De otro lado, el sentido de clandestinidad y persecución se diluyen para dar cabida a una aceptación en el imaginario colectivo urbano sin perder el derecho a la libertad de expresión y la plurisignificación que implica el grafiti a nivel histórico y social.

Esta nueva tendencia permite el acercamiento entre la gente proveniente del arte callejero y los artistas formados en diseño, plásticas, música e incluso gestores de política, quienes ven en este medio una forma de expresión masiva; por lo cual es difícil identificar si sus creadores conservan los intereses de los grafiteros tradicionales o es la manera anónima de dar a conocer un estilo y posteriormente, ser reconocidos social-

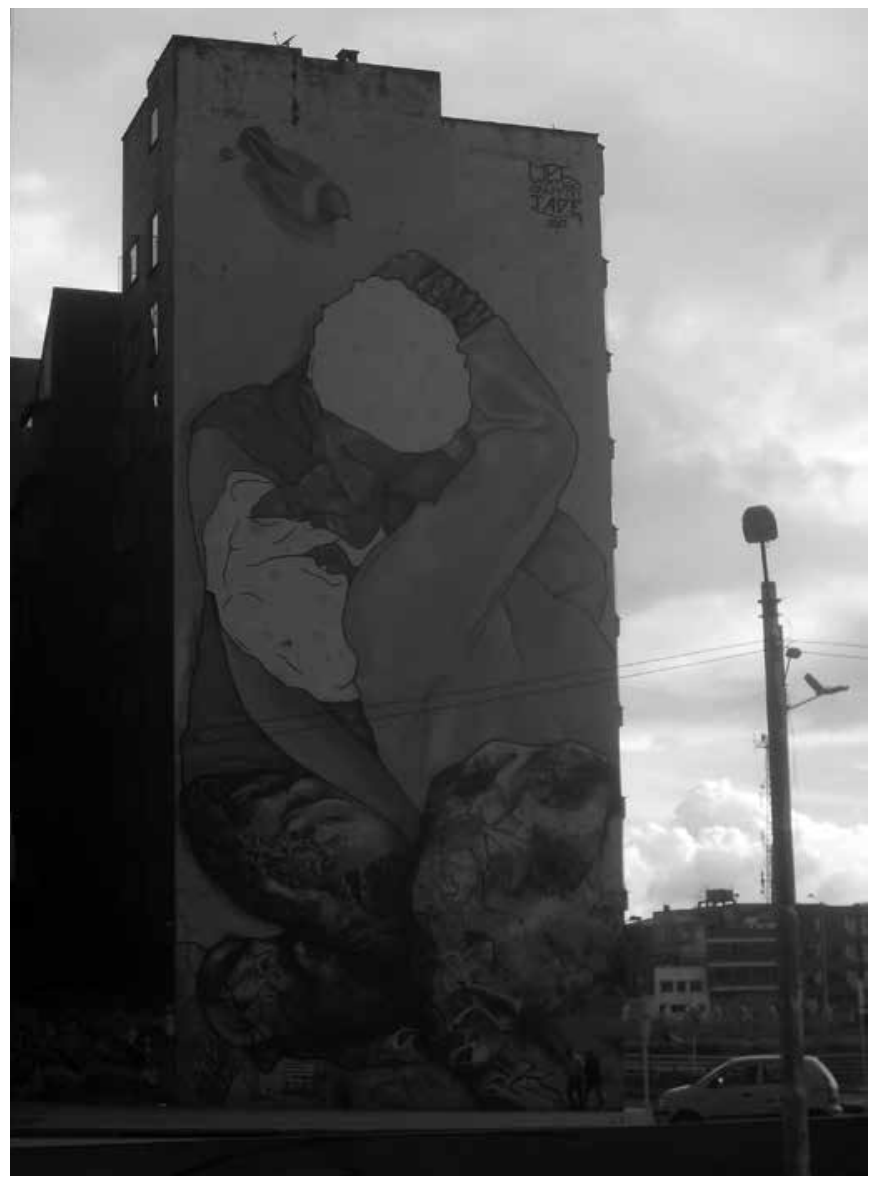

El beso francés. Bogotá, Calle 26 con avenida Caracas. Colección de César Correa Neira, 2014

mente. Finalmente, la pared en blanco siempre se convertirá en un deseo irresistible para quienes desean dejar huella con su grafiti (Silva, 2013).

\section{La escuela y el grafiti un terreno sin explorar}

La ciudad marginada, la imaginación castrada, la desesperanza de un futuro inexistente o manipulado y el deseo de rebeldía son los ingredientes que caracterizan la actitud de los adolescentes en los entornos escolares de nuestra Bogotá pública. Un contexto escolar donde la comunicación o el deseo de estar con el otro y para con el otro exige un nivel de información que se 


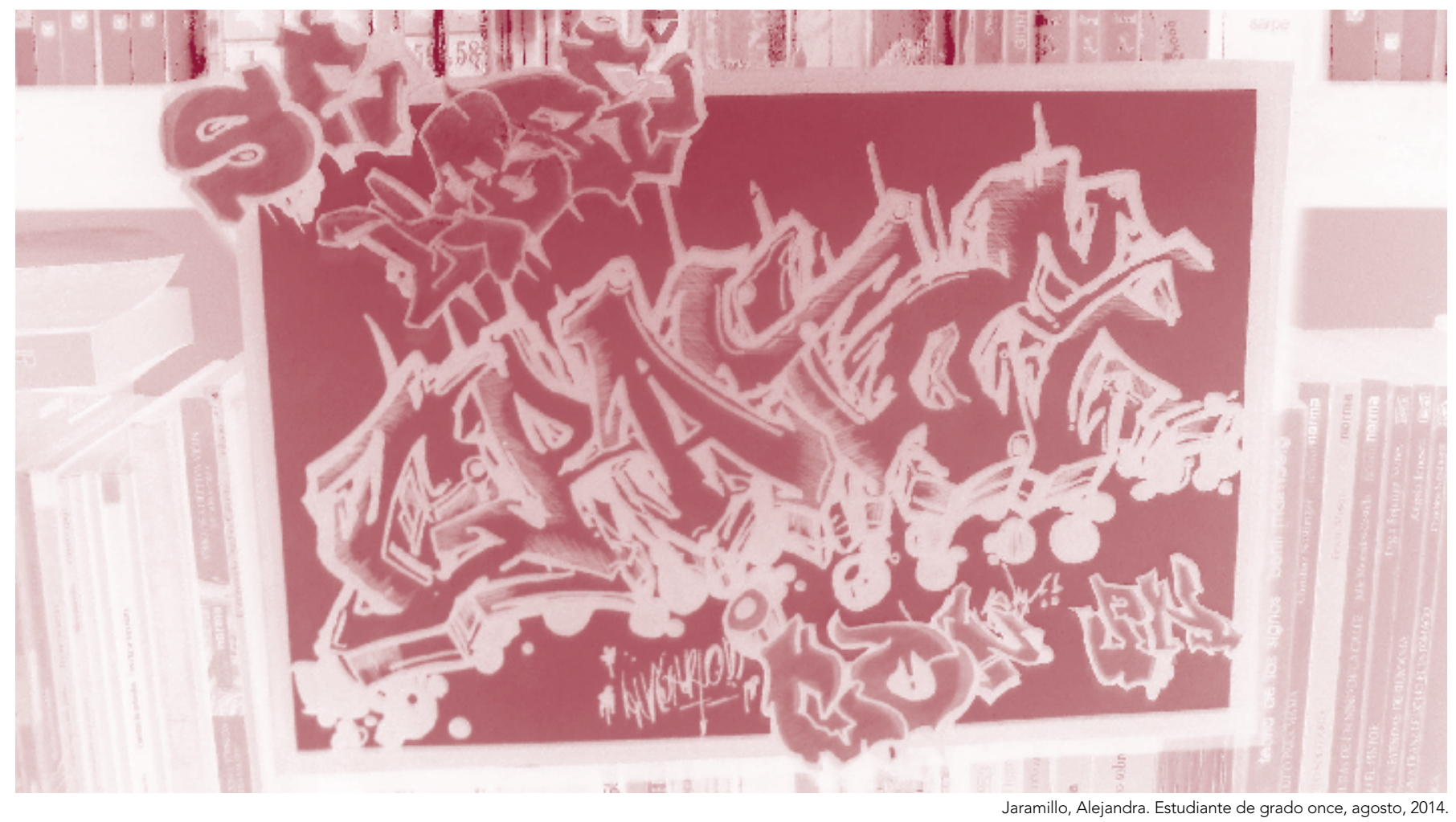

intercambia continuamente en cada palabra, mensaje, discurso o manifestación cultural. En consecuencia, el estudiante necesita ser reconocido y llamar la atención sobre experiencias inmediatas que definirán su rol en un contexto familiar, social, escolar y personal. La escuela como espacio de formación lucha por comprender y al mismo tiempo formar u orientar este vital material humano que se resiste o se resigna a su presente, cualquiera que sea.

Es así como el adolescente y el grafiti puede compartir un significado intrínseco en la perspectiva de sus propósitos y finalidades. Acaso el segundo no es un medio de expresión que censura las realidades y permite exteriorizar las ideologías o pensamientos ocultos e irreverentes que no son aceptados en una sociedad. No podemos negar tampoco que nuestros estudiantes, de manera clandestina, manejan códigos y lenguajes urbanos que tejen comunidad, revelan sus gustos, sus emociones, sus sentimientos, sus necesidades y aquellos se convierten en signos o símbolos que los identifican como grupo, subcultura o comunidad específica. Sin embargo, si observamos con nuestro ojo crítico podemos darnos cuenta de que el grafiti en las paredes, los baños y los pupitres de los colegios, son el testimonio de una producción textual que llama mucho la atención a nuestros estudiantes y logran despertar un interés creativo por su elaboración.

El grafiti como texto creativo comparte claramente una perspectiva sociocultural en términos de Vigotsky, contribuye en gran medida a rescatar esa dimensión plurisignificativa del lenguaje en sus diferentes funciones según Austin y promueve un proceso cognitivo e interactivo de la escritura como es expresada en la perspectiva psico-sociocultural de Cassany. En verdad, sería una lástima no aprovechar este texto como insumo del aprendizaje de la lengua en la escuela.

Acercándonos a la enseñanza y el aprendizaje de la escritura en la escuela, se podría consideran el grafiti como un texto estético, que en el buen sentido de la palabra, contiene una riqueza importante en su sintaxis, semántica y pragmática, ya que a nivel semiótico y discursivo plantea un análisis profundo de implicaciones sociales y culturales de quien y para quien lo 
produce. Además se convertiría en una estrategia metodológica y un pretexto para motivar al estudiante en su proceso escritor, logrando implementar herramientas y habilidades cognitivas que cualifiquen o incrementen su nivel de escritura en el texto mismo y en otras tipologías inmersas de la producción textual.

En concordancia con el potencial que puede ofrecer el grafiti en el entorno escolar se hace imprescindible enlazar este tipo de texto estético con el término de formación para la ciudadanía cuya finalidad es aprender a participar y coexistir en un mismo territorio bajo la participación y la democracia. Un proceso difícil si no se reconoce al ser como un sujeto inmerso en la comunidad con derechos y de deberes. También, se plantea la necesidad de pertinencia por parte del individuo de cada uno de los espacios públicos, políticos, económicos y culturales que hacen parte de la ciudad (Alderoqui y Penchasky, 2002). En cierta medida el grafiti expresa una posición crítica a la situación actual del ciudadano y la carencia de un equilibrio moral o ético en función de la participación y la democracia. En consecuencia, es allí donde la propuesta encaminada por la Secretaría de Educación en relación con los programa de formación de los estudiantes como seres comprometidos y críticos de su entorno urbano hace que la ciudad se convierta en un espacio de aprendizaje significativo.

\section{Conclusiones}

El grafiti se puede considerar un texto estético que posibilita la expresión y el discurso crítico de la vida urbana y social cargada de emociones, necesidades, luchas políticas, económicas y morales. También, manifiesta una diversidad de recursos estilísticos que crean una relación con la comunicación y el manejo simbólico del lenguaje en sus diferentes funciones lingüísticas y semióticas. Este texto estético nos brinda una mirada histórica en relación con su evolución y las diferentes características que los componen. Además, permite apreciar su funcionalidad comunicativa y los intereses que giran en el diseño, implementación e impacto en el contexto urbanístico de las ciudades donde se desarrolla.

La escuela como espacio de aprendizaje y formación de individuos críticos y reflexivos de sus necesidades y retos en la conformación de un proyecto de vida, considera las habilidades discursivas y en especial, la escritura como una herramienta comunicativa que los estudiantes deben fortalecer cada día. En consecuencia, el grafiti como texto estético se puede utilizar como estrategia metodológica para incrementar los niveles de escritura de los estudiantes y cualificar su mirada crítica de la realidad que los circunda.

\section{Referencias}

Alderoqui \& Penchansky, P. (2002). Ciudady ciudadanos. Aportes para la enseñanza del mundo urbano. Buenos Aires: Paidós.

Eco, U. (1986). La estructura ausente. España: Editorial Lumen.

Méndez, J. \& Garrido, S. (2002). El otro arte de escribir. Escuela de arte de Valladolid. Recuperado de www.valladolidwebmusical.org/graffiti/ historia/04historia1.html
Silva, A. (2003). Bogotá imaginada. Bogotá: Convenio Andrés Bello, Universidad Nacional de Colombia, Taurus. . (2006). Imaginarios urbanos. Bogotá: Arango Editores. . (2013). Atmósferas ciudadanas: grafiti, arte público, nichos estéticos. Bogotá: Universidad Externado de Colombia. 


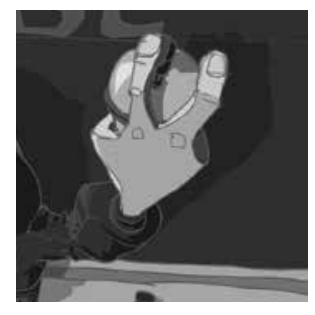

